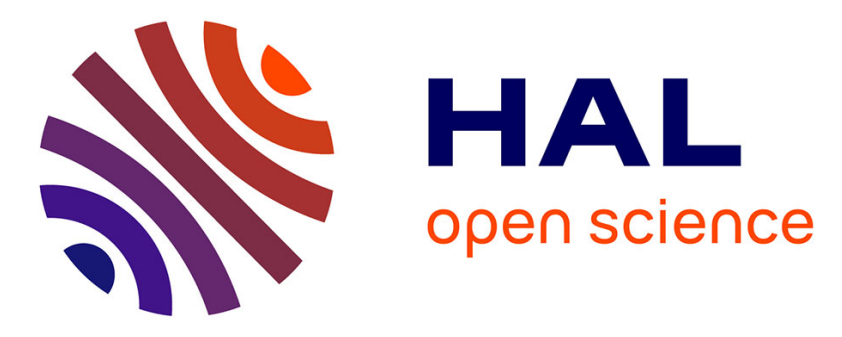

\title{
Partial Discharges in Aeronautics: The last frontier?
}

Thierry Lebey, Benjamin Cella, Thibaut Billard, Cédric Abadie

\section{To cite this version:}

Thierry Lebey, Benjamin Cella, Thibaut Billard, Cédric Abadie. Partial Discharges in Aeronautics: The last frontier?. ICPADM 2015 (11th International Conference on the Properties and Applications of Dielectric Materials), Jul 2015, Sydney, Australia. pp. 268-271. hal-01659579

\section{HAL Id: hal-01659579 https://hal.science/hal-01659579}

Submitted on 8 Dec 2017

HAL is a multi-disciplinary open access archive for the deposit and dissemination of scientific research documents, whether they are published or not. The documents may come from teaching and research institutions in France or abroad, or from public or private research centers.
L'archive ouverte pluridisciplinaire HAL, est destinée au dépôt et à la diffusion de documents scientifiques de niveau recherche, publiés ou non, émanant des établissements d'enseignement et de recherche français ou étrangers, des laboratoires publics ou privés. 


\section{Open Archive TOULOUSE Archive Ouverte (OATAO)}

OATAO is an open access repository that collects the work of Toulouse researchers and makes it freely available over the web where possible.

This is an author-deposited version published in : http://oatao.univ-toulouse.fr/ Eprints ID : 18251

To link to this article : DOI: 10.1109/ICPADM.2015.7295260

URL : http://dx.doi.org/10.1109/ICPADM.2015.7295260

To cite this version : Lebey, Thierry and Cella, Benjamin and Billard, Thibaut and Abadie, Cédric Partial Discharges in Aeronautics: The last frontier? (2015) In: ICPADM 2015 (11th International Conference on the Properties and Applications of Dielectric Materials), 11 February 2015 - 16 February 2015 (Orlando, United States).

Any correspondence concerning this service should be sent to the repository administrator: staff-oatao@ listes-diff.inp-toulouse.fr 


\section{Partial Discharges in Aeronautics: The last frontier?}

\author{
Thierry Lebey \\ LAPLACE, Université de Toulouse \\ 118 route de Narbonne \\ 31062 Toulouse, France \\ thierry.lebey@laplace.univ-tlse.fr
}

\author{
Benjamin Cella \\ Liebherr Elektronik GmbH \\ Peter-Dornier-Straße 11 \\ 88131 Lindau, Germany \\ benjamin.cella@liebherr.com
}

\author{
Thibaut Billard, Cédric Abadie \\ IRT Saint Exupéry \\ 118 route de Narbonne \\ 31432 Toulouse, France \\ thibaut.billard@irt-saintexupery.com \\ cedric.abadie@irt-saintexupery.com
}

\begin{abstract}
This paper presents the recent advances made in the field of Partial Discharges detection and analysis in the field of aeronautics. More particularly, it intends to present the influence of the voltage waveform on the type of detection method, the role of the assembly process on the PD Inception Voltage and finally an on line PD detection under PWM voltage. The influence of the pressure on the type and nature of the discharges is also discussed.
\end{abstract}

Keywords- Areonautics; Power Electronics; Partial Discharges detection;

\section{INTRODUCTION}

At the dawn of this new millennium, the increasing development of aerial mass transportation, as with sustainability concerns, have driven the main airplane manufacturers to change their design paradigms. In a first step, a particular attention has been drawn to the non-propulsive power systems. The main idea is to replace the combination of hydraulic, pneumatic, electrical and mechanical power by a More (and "All" in the future) Electrical Airplane philosophy consisting in an increasing use of power electronics and electric power conversion systems. Such systems are mainly constituted by Power Electronics converters (whose technology has made tremendous breakthroughs over the past decade) and actuation such as electromechanical actuators (EMA), electro-hydrostatic actuators (EHA), fault-tolerant electric motor/generators... "Bleedlesss" and "Hydraulicless" airplanes are already flying in commercial operations. This increasing demand for more electrical power "on board" (up to and sometimes higher than $1 \mathrm{MW}$ ) led to an increase of the voltage magnitude and/or to change its distribution logic on board (from AC to DC for e.g).

In the future, advanced studies predict the development of the use of electrical power for the propulsion itself. It appears therefore particularly important to focus our attention on insulating materials appearing as the weakest link for the reliability of these systems.

The aim of this paper is to draw a picture of the different works in progress in our laboratory in this field, taking into account aeronautic specificities. The first one, presenting commonalities with a large number of other applications like electric vehicle, or industrial applications, is the use of an electric powertrain. This one is constituted of an inverter generating, for example, a Pulse Width Modulated (PWM) Voltage whose magnitude may range (depending on a lot of parameters) from the DC Bus and up to 2 times the DC Bus [1], a cable whose length may vary from few centimeters to tens of meters, and of an electrical motor, usually manually wound. This last one may have successfully passed current inhouse validation and qualification tests as well as conventional procedures to assess insulation performance. Nonetheless, the motor may still fail prematurely in service.

On one hand, these conventional testing procedures using sinusoidal or unipolar surge voltage are not suited to qualify motor fed by an inverter drive. They may not be representative enough of the real electrical, mechanical and thermal stresses

On the other hand, electric motors, like other components, are designed in a cost-efficient way and often result in the choice of random-wound motors. Nevertheless, since there is no direct physics relating insulation materials properties and their performance under electrical stresses, most of design rules are based on experience, trial and errors.

The second specificity of aeronautics systems is associated to the environment: pressure may vary from atmospheric to as low as 100 mbars while the temperature may range from around $-60^{\circ} \mathrm{C}$ and up to $300^{\circ} \mathrm{C}$ (and more) [2]. Such harsh environment conditions are depending on the location of the system.

In summary, the technological locks here are the ability to safely and accurately measure partial discharge inception voltage in machines fed by inverters under operating conditions. These operating conditions may totally change the nature of the involved mechanisms, ie partial discharge (PD). In the first part of this paper, the methods to detect PD under the different possible voltage waveforms (AC, DC and PWM) are presented. Since the whole powertrain chain must be claimed «PD Free » to guarantee its reliability, it is necessary to test all the single equipments and - when possible - their constituents and finally their components to determine the manufacturing and assembly problems that may occur during industrial processes. These samples will also be presented in this part. In the second part, the results obtained at the different levels are summarized. Then, the detection on real systems is presented. Finally, the problems associated to the 
conditions of PD detection depending on the environmental conditions (pressure, temperature) are discussed.

\section{EXPERIMENTAL SET-UP AND SAMPLES UNDER STUDY}

\section{A. PD Detection systems}

Different PD detection systems are used depending on the voltage waveforms. For AC and DC, a classical system using either a Coupling Capacitor (CC) or a Current Transformer (CT) may be used [3]. For Bipolar Pulse (BP) voltages and PWM voltages, a coaxial sensor coupled to different high-pass filters is studied (Fig. 1)[4]. For these last measurements, it is important to notice that the oscilloscope must present a very large bandwidth $(>1 \mathrm{GHz})$ with a high sampling rate $(-\mathrm{GS} / \mathrm{s})$ [5].

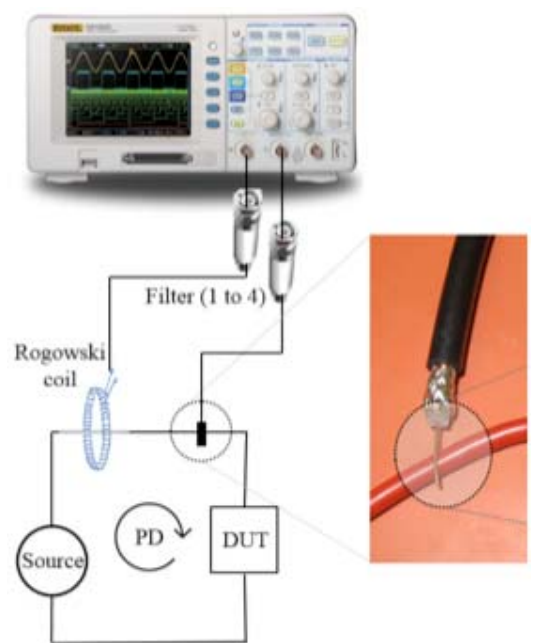

Fig. 1. Schematic representation of the system used to detect PD under $\mathrm{BP}$ and PWM voltages.

\section{B. Power supply : from simple source to real converters}

A fully configurable bipolar inverter drive associated with a high voltage power supply is used in order to feed different samples ranging from simple twisted pairs of enamel wires to stators with inverter-like signals. Technology used in this equipment has been chosen to create rise time comparable to real inverter drives. This equipment allows the ability to supply stators, either one phase at a time or three-phases at the same time, and to reach partial discharge inception threshold. Moreover, voltage waveforms are entirely adaptable so that this equipment is able to create a large range of inverter-like waveforms, from simplest to more complex ones, in order to test assumptions regarding the nature of the discharges.

For on line testing, the inverter type and characteristics are depending on the manufacturers "know-how" and no details (except the voltage waveforms) will be given in this paper.

\section{Samples under study: From constituents to real systems}

Different types of samples are made to match the different types of:

- Constituents (twisted pairs of enamel wires for the insulation of wound systems, vented samples for defects in Printed Circuit Board or capacitors...)
- Components (Auto Transfo Rectifier Units, Filters, Connectors, Powerboards...)

Systems (stators, real machines...)

Due to confidentiality concerns, no details on the two last types will be given, only their general behaviors are presented.

Fig. 2 gives an example of the samples under study

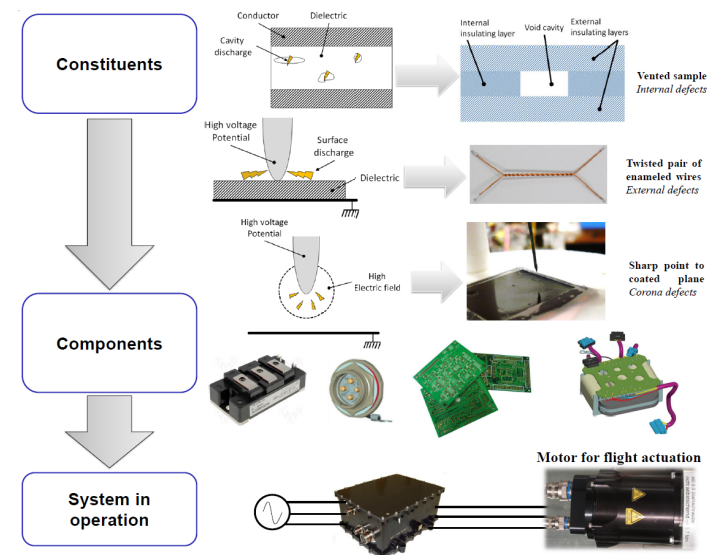

Fig. 2. The different types of samples under study.

\section{RESULTS AND DISCUSSION}

In a first step, the different types of stresses (AC/DC/BP/PWM) are applied to the different types of samples, supposed resistant enough to endure them. This approach allows determining the most likely PD detection system to be used as a function of the applied stresses. Not surprisingly, the detection and PD quantification under DC have been a difficult task that will not be discussed in this paper. The important result is that if PDs may be detected, their inception level is relatively high compared to the voltage used in service(either the rated or the transient) and when present, the repetition rate of $\mathrm{PD}$ is low[5].

The second step consists in determining the most appropriate detection method under $\mathrm{AC}$ voltage $(\mathrm{CC}, \mathrm{CT}$, coaxial sensor without filter). A comparison of the magnitude of the PD pulses for the different detection methods may be achieved on the simplest samples. The magnitude of the pulses detected, ranking in the decreasing order, is the classical detection system (due to the use of a pre-amplifier), the
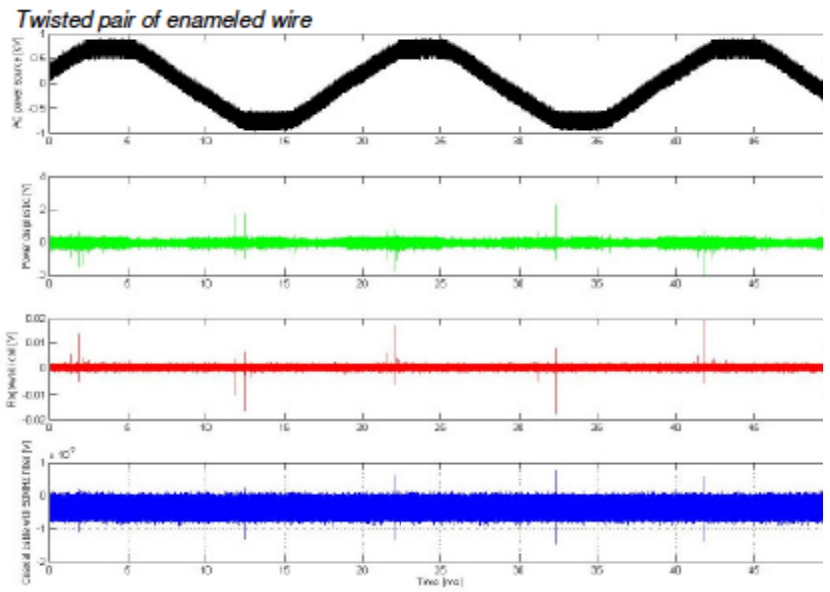

Fig. 3. Comparison of the different types of PD detection in a simple case 
Rogowski coil and the coaxial sensor. This result is not surprising at all (Fig. 3).

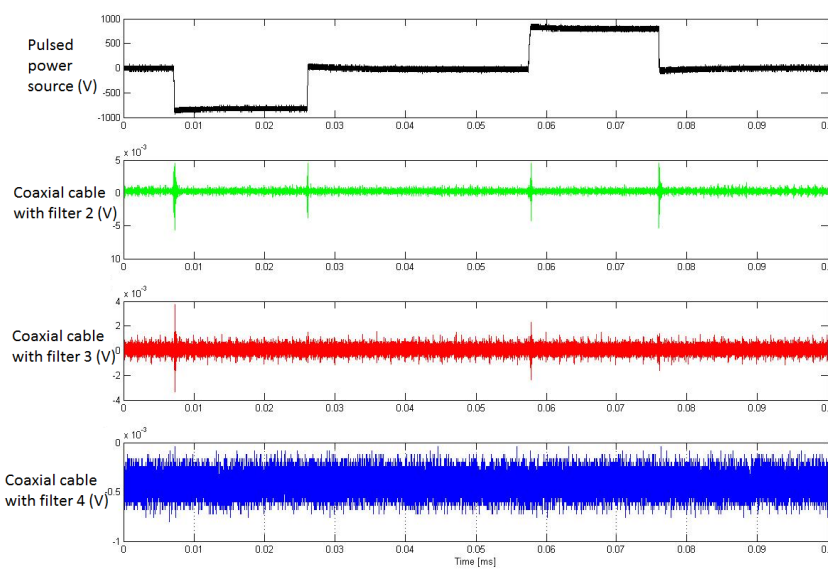

Fig. 4. Partial discharges and switching noise occurring simultaneously (Filter 2, Filter 3, Filter 4)

The influence of filtering on PD detection on samples submitted to pulse voltage or PWM voltage is then studied (Fig. 4). It is obvious that the filtering cut-off frequency plays a key role on the detection of PD. However, it is important to note that at atmospheric pressure, whatever the bandwidth of the filters, no difference on PDIV values is observed

On the contrary, when decreasing the pressure, PDIV seems to increase with the increase of the filter's cutoff frequency. Of course, this is not the case and this results only means that either the discharge nature is changing or that for the same nature of discharge its frequency content is modified. These points will be discussed in the following.

Finally, the detection is achieved on a real system consisting of a variable 3 phases AC power source $(400 \mathrm{~Hz}$, 4A) whose magnitude may be varied up to $320 \mathrm{~V}$ RMS (normal condition is $230 \mathrm{~V} \mathrm{RMS}$ ), feeding an inverter which is supplying an electrical motor (random wound) through a cable whose length may be adjusted. This voltage range is larger

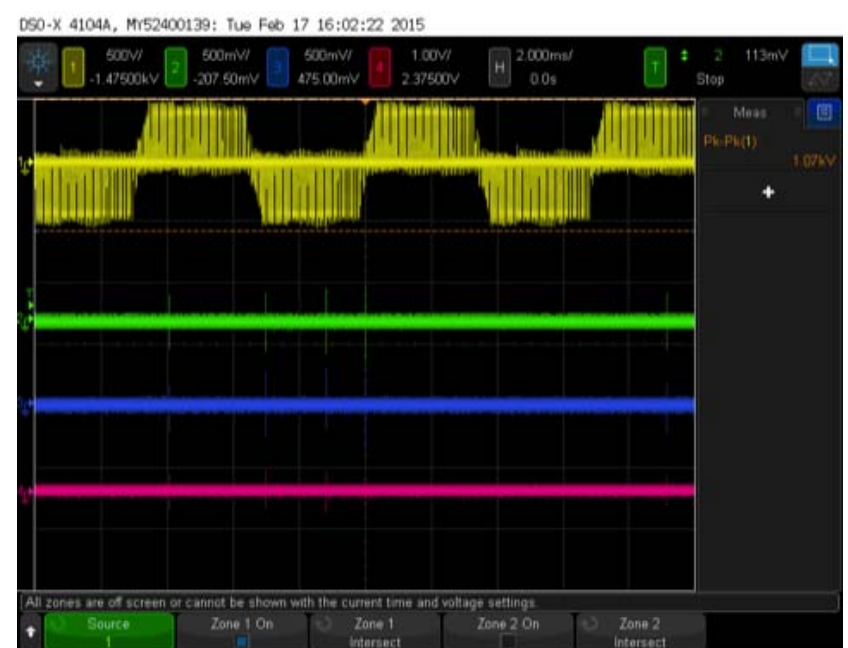

Fig. 5. PD detection using different cut-off frequency filters and sensors than the one supposed to be met in service but it gives us the opportunity to reach the PDIV (when it is reachable) and to test the validity of our approach regarding the detection achieved using the sensors presented in Fig. 1. Their output signal is filtered to remove the noise associated to the switchings.

Fig. 5 proves that it is possible to measure PDs during online operation of the power chain. Their magnitude is depending on the cut-off frequency of the filters.

The first interesting result is that the PDs observed have a very low repetition rate. It may also be deducted that PDs when they exist are produced on one polarity and during the polarity reversal and not at the switching frequency. Such a behavior allows determining their location through the observation of the 3 phase-to-phase voltages (Fig. 6).

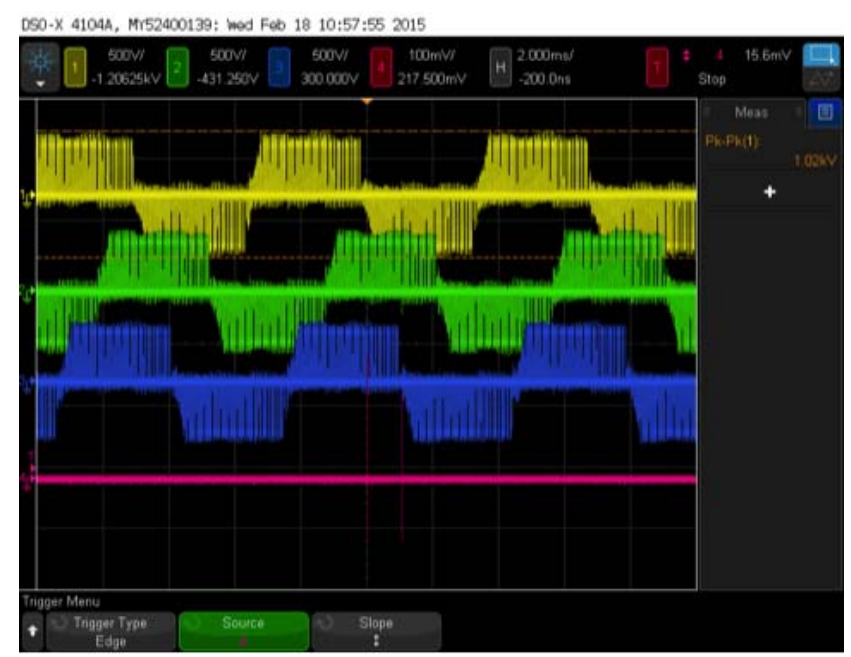

Fig. 6. PD detection and phase-to-phase location (here on the blue).

Such a behavior has already been reported [6] and has been associated to a glow discharge whose theoretical behavior is reminded in Fig. 7. The existence of the very high frequency components presents in the high $\mathrm{dV} / \mathrm{dt}$ would be responsible of the glow formation at atmospheric pressure since the same behavior is not observed under $\mathrm{AC}$ at the same switching frequency (i.e at the fundamental frequency of the PWM voltage).

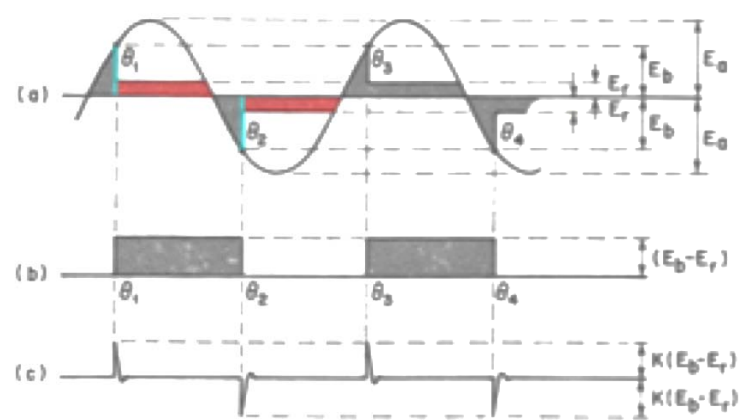

Fig. 7. Schematic representation of Glow discharge behavior [5] 


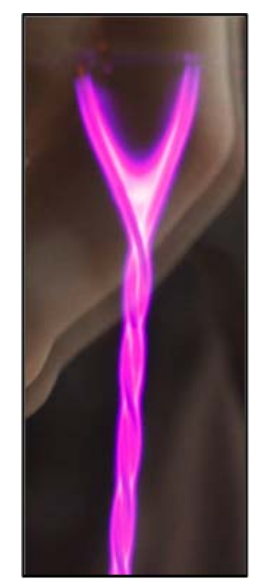

Fig. 8. Discharge observed at low pressure in a twisted pair of enamel wires fed by Pulse like voltage.

Therefore, PD detection in such harsh environment proves to be possible (even if relatively difficult) at atmospheric pressure. However, when the pressure decreases, as it is the case for aeronautics systems used in depressurized area, it is obvious that the discharges switch to glow type (see Fig. 8) but in that case and for some pressure value the electrical detection may not be possible anymore. One possible explanation is the changes in the frequency components of the discharge associated to a change in its nature. More work is necessary to clarify this situation.

\section{CONCLUSION}

The main conclusion of this paper is the efficiency of the method. A simple and stripped coaxial cable is able to detect PD during AC conditions and, by adding a high pass filter, PD can be dissociated from switching noise under PWM-like voltage. Among the different possibilities, the filter 3 proved to be the most efficient. The different types of defects (External, Internal, and corona) that can exist in a real environment have been tested, each of them showing that PD can be detected by this method.

Since some advanced studies imagine that in the future the propulsion itself could be electrical thus leading to use real high voltage $(>1 \mathrm{kV})$, this" hybridization" of the engines will certainly lead to new and interesting challenges for the study of electrical insulation.

\section{REFERENCES}

[1] E. Persson, "Transient effects in application of PWM inverters to induction motors," IEEE Trans. Ind. Appl., vol. 28, no. 5, pp. 10951101, Sep. 1992.

[2] F. Koliatene, T. Lebey, J.-P. Cambronne, and S. Dinculescu, "Impact of the aeronautic environment on the Partial Discharges Ignition: A basic study," in Conference Record of the 2008 IEEE International Symposium on Electrical Insulation, 2008. ISEI 2008, 2008, pp. 603606.

[3] F. H. Kreuger, Partial discharge detection in high-voltage equipment. Butterworths, 1989.

[4] T. Billard, T. Lebey, and F. Fresnet, "Partial discharge in electric motor fed by a PWM inverter: off-line and on-line detection," IEEE Trans. Dielectr. Electr. Insul., vol. 21, no. 3, pp. 1235-1242, Jun. 2014.

[5] R. Bartnikas and E. McMahon, Eds., Engineering Dielectrics Volume I Corona Measurement and Interpretation. 100 Barr Harbor Drive, PO Box C700, West Conshohocken, PA 19428-2959: ASTM International, 1979.

[6] T. Billard, T. Lebey, A. Belinger, N. Naude, and N. Gherardi, "On the nature of the discharges in samples fed by bipolar pulse like voltage and its possible impact on the detection of partial discharge in machines fed by inverter," in Proceedings of 2014 International Symposium on Electrical Insulating Materials (ISEIM), 2014, pp. 200-203. 